\title{
Causes of mortality in free-living Mauritian pink pigeons Columba mayeri, 2002-2006
}

\author{
Nancy Bunbury ${ }^{1,2,5, *}$, Mark F. Stidworthy ${ }^{3}$, Andrew G. Greenwood ${ }^{3}$, Carl G. Jones ${ }^{2,4}$, \\ Shiva Sawmy ${ }^{2}$, Ruth E. Cole ${ }^{2}$, Kelly Edmunds ${ }^{1,2}$, Diana J. Bell ${ }^{1}$ \\ ${ }^{1}$ Centre for Ecology, Evolution and Conservation, School of Biological Sciences, University of East Anglia, \\ Norwich NR4 7TJ, UK \\ ${ }^{2}$ Mauritian Wildlife Foundation, Grannum Road, Vacoas, Mauritius \\ ${ }^{3}$ International Zoo Veterinary Group, Keighley Business Centre, South Street, Keighley, W. Yorkshire BD21 1AG, UK \\ ${ }^{4}$ Durrell Wildlife Conservation Trust, Les Augrès Manor, Trinity, Jersey JE3 5BP, Channel Islands, UK \\ ${ }^{5}$ Present address: Seychelles Islands Foundation, La Ciotat Building, Mont Fleuri, PO Box 853, Victoria, Mahe, Seychelles
}

\begin{abstract}
With disease playing an often unknown role in populations of endangered species, necropsy studies are an important component of conservation management programmes. In the present study, we investigate causes of mortality in the free-living population of endangered pink pigeons Columba mayeri, endemic to Mauritius. Fifty carcasses of free-living pink pigeons were found over a 5 yr period between January 2002 and December 2006. Causes of mortality and other post-mortem findings are reported for 43 of these birds, which were aged between 6 wk and 15 yr. The protozoan disease trichomonosis was the most common cause of death, with $22(52 \%)$ freshly dead birds identified as dying from this disease. Four birds were suspected to have been killed by introduced mammalian predators, 4 died as the result of an impact injury and most of the remaining birds either died of unknown causes or the carcasses were too decomposed for necropsy. Our study highlights trichomonad protozoal infections as an important mortality factor in post-fledging pink pigeons in recent years. A number of other novel or rarely described parasites are also identified, highlighting the relative paucity of knowledge on background levels of parasitism in free-living endangered species.
\end{abstract}

KEY WORDS: Conservation management · Disease · Mauritius · Necropsy · Predation · Trichomonosis

\section{INTRODUCTION}

Although disease is gaining increasing recognition as a significant contributory factor to global avian declines and extinctions (e.g. Osofsky et al. 2000, Friend et al. 2001, Weimerskirch 2004), Smith et al. (2006) found that infectious disease was listed as contributing to less than $4 \%$ of species extinctions since 1500 and less than $8 \%$ of cases in which a species was classed as critically endangered. This might suggest that disease as a causal factor in population declines and extinctions is under-reported. Disease surveillance studies, therefore, play a valuable role in conservation management or recovery programmes for endangered avian species. Such studies should include the investigation of causes of mortality by standardised necropsy, with histopathology if resources permit, of recovered carcasses. Such an approach can provide vital information on significant mortality factors in the study population which may otherwise be overlooked.

The Mauritian pink pigeon Columba mayeri has been restored from a population of less than 20 birds in the 1970 s to approximately 380 birds today by an intensive conservation management and monitoring 
programme (Jones \& Hartley 1995, Bunbury 2006). The main drivers of the pink pigeon population decline originally included large-scale habitat destruction and predation by introduced mammals (Jones 1987), but parasitic disease may also have contributed (Swinnerton et al. 2005a). Disease remains one of several current threats to the species' long-term persistence. Causes of mortality have not been comprehensively studied in post-fledging free-living pink pigeons, so the relative importance of different mortality factors, such as disease and predation, is unknown. Diseases of particular concern include avian trichomonosis (Swinnerton et al. 2005a, Bunbury et al. 2008) and leucocytozoonosis (Peirce et al. 1997, Swinnerton et al. 2005b, Bunbury et al. 2007).

Avian trichomonosis is caused by the flagellate protozoan Trichomonas gallinae, and primarily affects Columbiformes, although it has been reported in a number of other avian orders worldwide (see Forrester \& Foster 2008). The parasite is transmitted directly, via mutual feeding or from parent to nestling, or indirectly via water or food (Stabler 1954). Signs of trichomonosis include yellowish caseous lesions and/or necrotic ulcerations in the upper digestive and respiratory tracts, a foul cheesy smell emanating from the gape, and swelling of parts of the head such as the eyes or nares (for a more detailed description of the disease and parasite life-cycle see Stabler 1954, Bunbury et al. 2008). Trichomonosis is known to cause high mortality in pink pigeon squabs (Swinnerton et al. 2005a) and, in 2004, was responsible for squab mortality of up to $77.5 \%$ in 1 subpopulation (Bunbury 2006).

Long-term population monitoring facilitated this investigation into the causes of adult pink pigeon mortality over a $5 \mathrm{yr}$ period between 2002 and 2006. This is a key time period in which to examine mortality for this species, because the total population size has remained relatively stable since 2001, following a rapid, $10 \mathrm{yr}$ increase. The primary objective of this paper is, therefore, to investigate significant causes of mortality in free-living pink pigeons based on necropsy examinations of individuals which died during this period. We use the findings to help elucidate the reasons for the lack of continued population recovery and to suggest directions for further research into disease and other mortality factors in this and other endangered avian species.

\section{MATERIALS AND METHODS}

Study area. There are 5 free-living pink pigeon subpopulations in Mauritius, all of which are managed by the Mauritian Wildlife Foundation (MWF) in cooperation with the governmental National Parks and Conservation
Service. Four of these subpopulations, Plaine Lievre (PL; $\left.20^{\circ} 38^{\prime} \mathrm{S}, 57^{\circ} 45^{\prime} \mathrm{E}\right)$, Pigeon Wood ( $\mathrm{PW} ; 20^{\circ} 44^{\prime} \mathrm{S}$, $\left.57^{\circ} 48^{\prime} \mathrm{E}\right)$, Bel Ombre $\left(\mathrm{BO}^{\circ} 20^{\circ} 28^{\prime} \mathrm{S}, 57^{\circ} 25^{\prime} \mathrm{E}\right)$ and Combo $\left(20^{\circ} 47^{\prime} \mathrm{S}, 57^{\circ} 51^{\prime} \mathrm{E}\right)$, are located in the Black River Gorges National Park in the south-west of Mauritius, and the fifth occurs on the offshore islet of Ile aux Aigrettes (IAA; $20^{\circ} 42^{\prime} \mathrm{S}, 57^{\circ} 73^{\prime} \mathrm{E}$ ). In each of these subpopulations, all pink pigeons are individually ringed with a unique metal and colour ring combination, and survival is monitored on a daily basis, enabling accurate recording of dates of disappearance or death and individual identification of any carcasses found.

Gross necropsy. Carcasses of juvenile (post-fledging to 6 mo of age) and adult pink pigeons recovered by members of the MWF staff during field-work between January 2002 and December 2006 were collected and, if fresh, stored at 0 to $5^{\circ} \mathrm{C}$ until gross necropsy. Any pink pigeons which died while being held temporarily in captivity for treatment or recuperation were necropsied within $24 \mathrm{~h}$ of death. All gross necropsy and histopathology examinations were conducted by one or more of the authors. Only relatively fresh pink pigeon carcasses (no or minimal signs of autolysis) underwent both gross necropsy and tissue sampling for histopathology. Moderately decomposed carcasses, which were visibly autolysed but in which the internal organs were intact and recognisable, were gross necropsied only, to search for the presence of lesions or other gross abnormalities. Severely decomposed carcasses with barely recognisable internal organs were given a cursory examination to try to determine cause of death. Necropsies followed a standard protocol based on those previously described (Waine 1996, Cooper 2004, Rose 2005). Where possible, all organs were examined, even in cases where the cause of death was known. Findings were recorded consistently using a standardised report template.

Over the 5 yr period, 50 carcasses were recovered from a total of 280 ringed pink pigeons which died or disappeared from the free-living population during this time (i.e. $17.6 \%$ of carcasses were recovered). The majority of birds, therefore, disappeared without trace. Eight of the 50 carcasses had undergone severe deterioration, so necropsy was not feasible. For 7 of these latter cases, it was not possible to diagnose a cause of death, but 1 carcass was found underneath a window with a cervical dislocation, so impact trauma was recorded as the probable cause of death. Full gross necropsy was conducted on 38 of the remaining 42 cases.

Gross post-mortem signs of trichomonosis include swollen eyes and head with the presence of caseous lesions, usually visible in the buccal cavity and oropharynx, but potentially occurring in virtually any organ in the body. Death caused by impact injury was evident either from obvious fatal injuries, e.g. broken 
bones, or large haematomas. Signs of predation included teeth marks, chewed bones, flesh and/or feathers, removal of characteristic parts of the carcass, footprints, and scattered feathers and/or traces of fur on the ground close to the carcass. Since it is usually impossible to distinguish between actual predation and post-mortem scavenging, all deaths thought to have been due to predation were recorded as 'suspected predation'. However, in all such cases, carcasses were examined closely for other potential causes of death. All other confirmed causes of death were single cases. Cause of death was recorded as 'unknown' if neither gross necropsy nor histopathology revealed a clear cause. All parasites found were collected and preserved in ethanol for later identification.

Histopathology. Tissue samples were collected for histological examination from all carcasses which were not excessively decomposed. These were fixed in $10 \%$ formalin and included samples of brain, spinal cord, eye, vertebral bone and bone marrow, pectoral muscle, skin with feather, heart muscle and pericardium, great vessels, spleen, oesophagus, proventriculus, ventriculus, duodenum, pancreas, liver, ileum, colon, cloaca, trachea, lung, kidney, thyroid, parathyroid, adrenal gland, testis or ovary and oviduct. Sections of any abnormal or diseased tissue were included and, where possible, these samples included the interface with healthy tissue. The complete set of formalin-fixed tissues was processed routinely to paraffin, and $4 \mu \mathrm{m}$ sections cut and stained with haematoxylin and eosin for light microscopic examination. All available tissues from each case were examined histologically by a single pathologist (M.F.S.) who had access to the recorded findings of the field necropsy examination. Additional special stains were selected by the pathologist as required.

\section{RESULTS}

Of the 42 recovered pink pigeon carcasses, 4 were found soon after death but in an incomplete state due to predation and/or scavenging, so detailed necropsies were not possible. All 4 were recorded as suspected predation, but it was not possible to identify the predator species. Of the necropsied birds 16 were male, 17 were female and 5 were juveniles of undetermined sex. The mean age of the 38 necropsied birds was $3.2 \mathrm{yr} \pm 0.6 \mathrm{SE}$, and age at death ranged from $6 \mathrm{wk}$ to $11 \mathrm{yr}$ (one depredated and non-necropsied bird was 15 yr and 7 mo of age at death).

\section{Trichomonosis}

The most commonly identified cause of mortality in juvenile and adult pink pigeons during this period was trichomonosis (22 cases, $52.4 \%$ of the 42 freshly recovered carcasses; Table 1, Fig. 1), including 9 males and 11 females. The mean age of birds which died as a result of trichomonosis was $3.7 \mathrm{yr} \pm 0.9 \mathrm{SE}$. In most cases, lesions were present in the upper digestive tract (Fig. 1A), including the mandibular region, oropharynx, soft and hard palates, tongue, oesophagus, crop and proventriculus, but lesions were also found in the sinuses and/or orbits (3 cases; Fig. 1B) and the anterior thorax (3 cases). In these latter cases, the lesions involved many organs, including the heart, sternum, pectoral muscle, great vessels, trachea and bronchi, and gizzard, forming a mass of inseparable material (this material has been confirmed histologically as trichomonosis in 2 of these cases and tissues from the third case have yet to be examined histologically). All 3 birds with this particularly severe form of the disease were from the $\mathrm{BO}$ subpopulation.

\section{Other causes of death}

In addition to trichomonosis and predation, several other causes of death were identified (all recorded as 'other' in Table 1). One 2 mo old juvenile from the PL subpopulation showed ante-mortem neurological signs consistent with the post-mortem finding of intracranial haemorrhage. The deaths of 2 adult males also from this subpopulation were caused by great vessel rupture and choking on food material, respectively. One PW adult with a suspected joint problem dislocated both tarsal joints and died during the lengthy recuperation period. A PW juvenile was discovered

Table 1. Columba mayeri. Causes of pink pigeon mortality in each subpopulation as determined from necropsies on carcasses found from 2002 to 2006. PL: Plaine Lievre; PW: Pigeon Wood; BO: Bel Ombre; IAA: Ile aux Aigrettes; na: not applicable

\begin{tabular}{|c|c|c|c|c|c|c|c|}
\hline Cause of death & PL & PW & $\mathrm{BO}$ & IAA & Combo & Total & $\%$ of total \\
\hline Trichomonosis & 6 & 0 & 5 & 8 & 3 & 22 & 51.2 \\
\hline Impact & 1 & 0 & 2 & 1 & 0 & $4^{\mathrm{a}}$ & 9.3 \\
\hline Predation & 1 & 0 & 2 & $n a^{c}$ & 1 & $4^{\mathrm{b}}$ & 9.3 \\
\hline Other & 3 & 2 & 0 & 0 & 1 & 6 & 14.0 \\
\hline Unknown & 1 & 1 & 0 & 5 & 0 & 7 & 16.3 \\
\hline Total & 12 & 3 & 9 & 14 & 5 & 43 & - \\
\hline \multicolumn{8}{|c|}{$\begin{array}{l}\text { ancludes } 1 \text { decomposed carcass found underneath a window with a cervical } \\
\text { dislocation (not necropsied) } \\
\text { b No necropsy due to incomplete carcass state } \\
{ }^{\mathrm{c}} \text { There are no predators of fledged pink pigeons on IAA }\end{array}$} \\
\hline
\end{tabular}



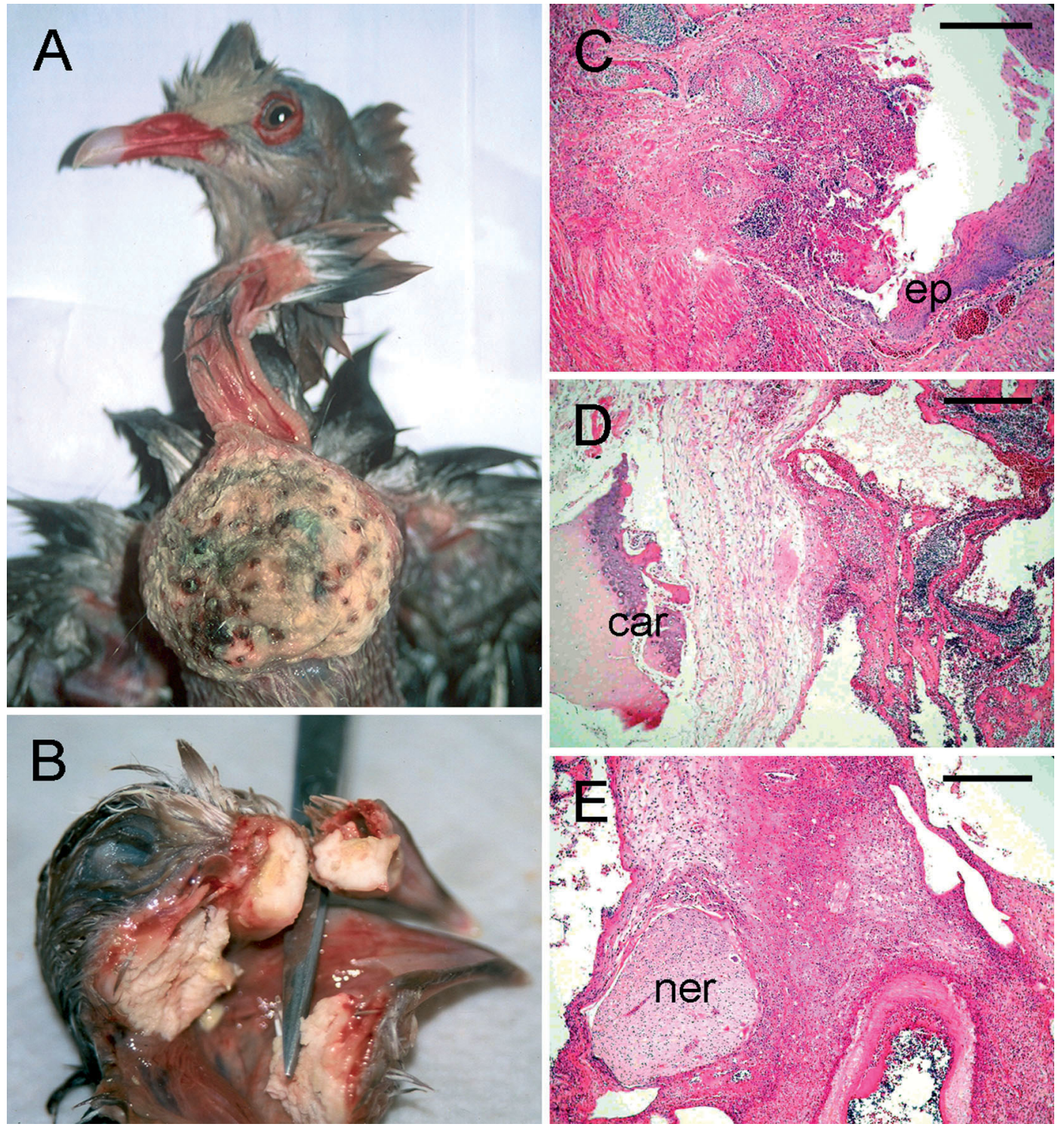

Fig. 1. Columba mayeri. (A) Characteristic trichomonosis lesions in the crop of an adult pink pigeon. (B) Extensive pharyngeal, nasal and oral trichomonosis lesions in a pink pigeon juvenile. (C) Fibrinonecrotic lesion of trichomonosis centred on the crop epithelium (ep); scale bar $=100 \mu \mathrm{m}$. (D,E) Extension of necrotic lesion into thoracic connective tissue and cartilage (car) and nerve bundle (ner); scale bars $=250 \mu \mathrm{m}$. $(\mathrm{C}-\mathrm{E})$ Haematoxylin and eosin staining

impaled on a barbed wire fence and probably died of resulting haemorrhaging. Finally, an adult female from the Combo subpopulation was found to have a severe cestode infestation.

No diagnosis was reached for 7 of the 38 carcasses, although predation and impact could be ruled out as a cause of death in each of these cases. Tissue samples from only 1 of these 7 birds have so far been examined histologically, revealing subcutaneous hypopial mites and hepatitis of unknown aetiology. Further histological examination on the samples from the 6 other birds may reveal their cause of death.

\section{Incidental findings and histopathology}

Histopathological examination confirmed the majority of gross necropsy diagnoses and detected several further incidental findings of note. One PL adult male which died of severe trichomonosis also had asymmetrical renal atrophy containing heavy urate deposits and a suspected trematode infection. Histopathology revealed granulomatous nephritis associated with intrarenal trematode infection. The species was putatively identified as Paratanaisia sp. (Fig. 2), probably P. bragai (Santos 1934), constituting only the second 

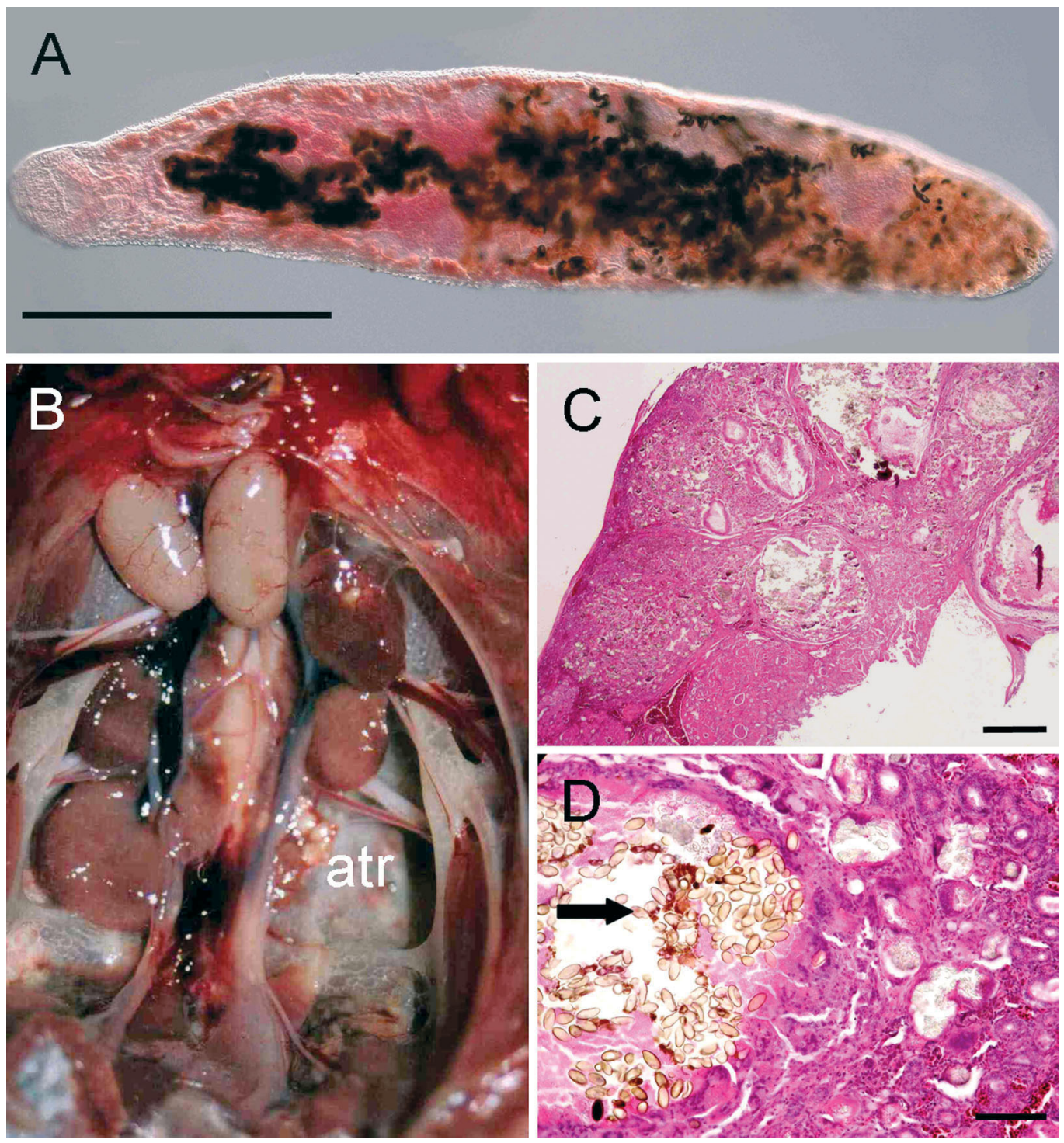

Fig. 2. Paratanaisia infecting Columba mayeri. (A) Renal worm identified as Paratanaisia sp., almost certainly P. bragai (Santos 1934) (morphology suboptimal due to formalin fixation; scale bar $=1 \mathrm{~mm}$ ). (B) C. mayeri kidneys. Asymmetrical renal atrophy (atr) and granulomaous inflammation. $(\mathrm{C}, \mathrm{D})$ C. mayeri. Multifocal to coalescent graulomatous inflammation around operculate trematode eggs (arrow) with urate tophi in adjacent kidney. (C) Scale bar $=500 \mu m_{i}$ (D) scale bar $=100 \mu \mathrm{m}$. Haematoxylin and eosin staining

report of this parasite in the pink pigeon. A PL adult female, which died of internal bleeding caused by an impact, was also found to have a prolapsed and histologically inflamed cloaca. Another PL female, which died at $11 \mathrm{yr}$ of age and had been diagnosed with a ruptured air-sac at gross necropsy, was later found to have an acute trichomonad infection, focally collapsed and distorted lungs and lens cataracts, which presumably impaired her vision. Five pigeons from IAA, all of which died in July and August 2004, were infected with subcutaneous heteromorphic deuteronymph mites of the family Hypoderatidae, identified as Нypodectes propus (Fig. 3), which have not previously been reported in pink pigeons. In none of these cases were the mites considered to be the primary cause of death or associated with significant lesions.

\section{DISCUSSION}

The examination of dead or moribund birds can be valuable either for diagnosis, in which the cause of disease or death in an individual or population is of interest, or for health-monitoring, by providing data on the background health status of an individual or population (Cooper 2004). This study combined both of the 


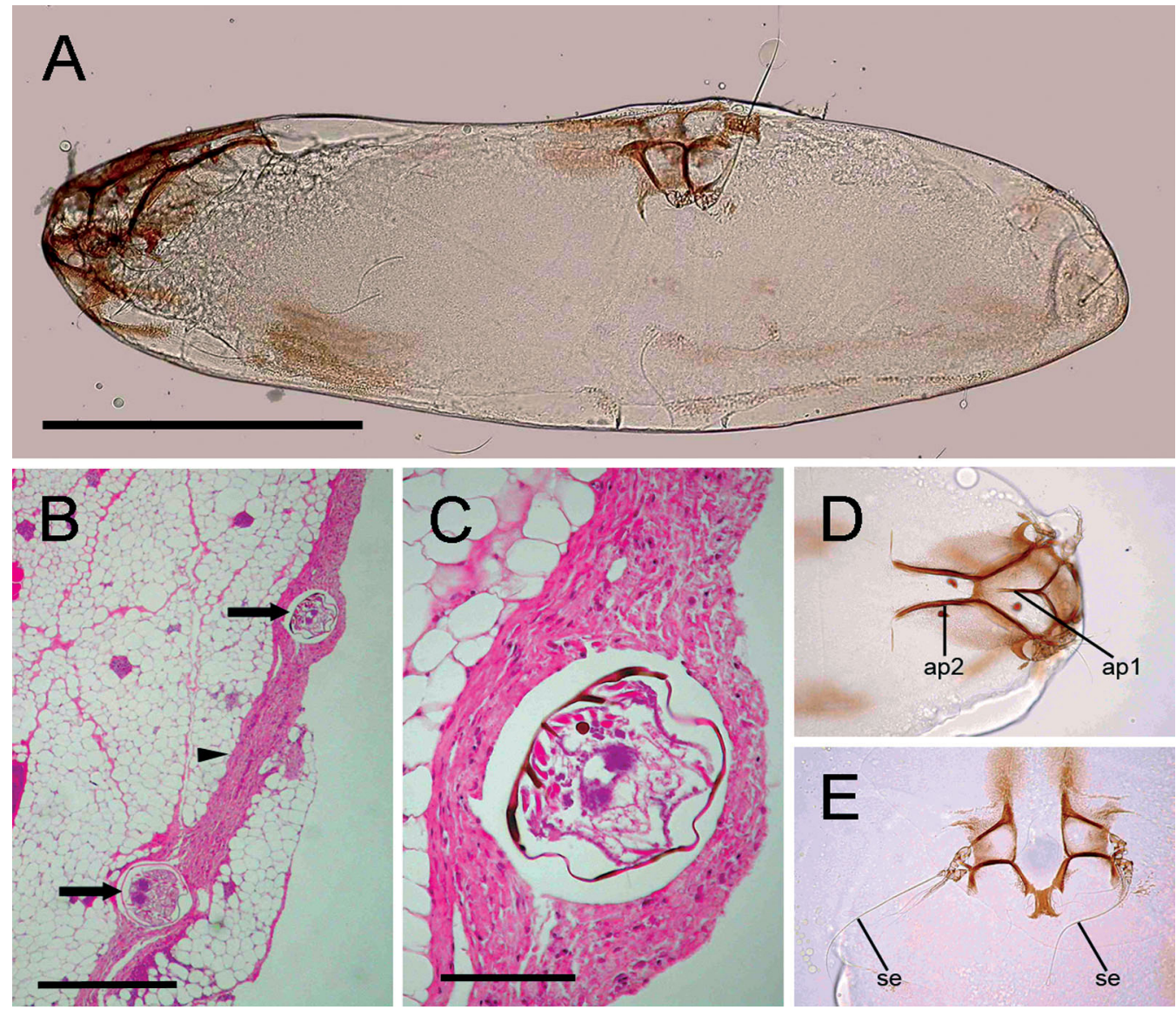

Fig. 3. Hypodectes propus. Hypopial mites. (A) Idiosoma of motile hypopus (scale bar $=300 \mu m$ ). (B,C) Subcutaneous hypopi (arrows) within pectoral fascia (arrowhead). Note the absence of inflammatory reaction around the parasites. $(B)$ Scale bar $=$ $500 \mu \mathrm{m}$; (C) scale bar $=100 \mu \mathrm{m}$. (D) Apodemes 1 (ap 1) and 2 (ap 2) and absence of gnathostoma, anterior hypopus. (E) Tarsi III and IV with long seta (se), mid-hypopus

above by (1) determining the major causes of mortality in pink pigeons from carcasses recovered between 2002 and 2006 and (2) providing preliminary data on other parasites which may influence the current/future survival of individuals.

Animal carcasses are generally difficult to locate in the wild due to scavenging and rapid decomposition, particularly in a tropical climate. Although the majority of the pink pigeons which died over the period of our study disappeared, the remains of almost $20 \%$ of these birds were recovered. This is a relatively high recovery rate of carcasses from a wild population and reflects the intensive monitoring conducted at all pink pigeon subpopulations. The primary cause of mortality in freshly recovered pink pigeon carcasses was trichomonosis, followed by predation and accidental impact injuries.

Trichomonosis is common in columbids worldwide and, although the disease has been widely studied in domestic pigeons and game birds such as the mourning dove Zenaida macroura (e.g. Greiner \& Baxter
1974, Conti 1993, Schulz et al. 2005) and the wood pigeon Columba palumbus (e.g. Höfle et al. 2004), its effects on endangered columbids other than pink pigeons have rarely been investigated (but see Harmon et al. 1987). In pink pigeons, trichomonosis was clearly a major cause of post-fledging mortality, accounting for the deaths of at least $52 \%$ of the 42 freshly found remains in our study. This is significant for the species' conservation because it provides direct evidence that the disease causes high mortality after fledging and expands on previous studies which have highlighted Trichomonas gallinae infection as (1) being a primary cause of mortality in squabs (Swinnerton et al. 2005a, Bunbury 2006) and (2) reducing long-term survival in adults with persistent infections (Bunbury et al. 2008). Interestingly, all 3 birds which died of the most severe form of trichomonosis in the anterior thorax were from the BO subpopulation, which has shown a marked decline since 2000 (Bunbury 2006). It is possible that a different, more virulent strain of T. gallinae is present in this subpopulation, 
and further research into T. gallinae strain differences between sites and columbid species is underway to investigate this (see Gaspar da Silva et al. 2007). Mortality studies of other endangered or declining columbids are also required to assess the extent of the risk posed by $T$. gallinae to such taxa, and to avian predators of columbids, which are also susceptible to T. gallinae infection (e.g. Real et al. 2000, Samour 2000, Krone et al. 2005), worldwide.

In the present study, no deaths were attributed to leucocytozoonosis and no signs of Leucocytozoon marchouxi infection were recorded in gross necropsy or histopathology examination (13 birds which were screened for blood parasites and included in this study all tested negative for $L$. marchouxi infection). Prevalence of $L$. marchouxi in the adult pink pigeon population was $18.6 \%$ in 2003, and infection was found to reduce survival probability (Bunbury et al. 2007). This suggests that L. marchouxi infection may be playing a contributory role in mortality, possibly through coinfection with Trichomonas gallinae or by increasing infected birds' susceptibility to predation.

Introduced predators are a major threat to many island avian species (Atkinson 1996, Jones 2004). On mainland Mauritius, several species of introduced mammalian predators, including the long-tailed (or crab-eating) macaque Macaca fascicularis, feral cat Felis catus and lesser Indian mongoose Herpestes auropunctatus, are known to prey on adult, juvenile and nestling pink pigeons (Jones 1987, Roy 2001, N. Bunbury pers. obs.). Predation is thought to be a common cause of death in pink pigeons at all sites except IAA, which has been cleared of all mammalian predators. Unfortunately, predation can rarely be confirmed as a cause of death, unless the bird is observed being attacked or found immediately after an attack, because signs of predation can be identical to those of scavenging. Caution should therefore be taken when assuming that predation is responsible for deaths which may have been due to other causes (e.g. disease or injury) and the remains later scavenged. Such prudence is likely, however, to compound the underestimation of predator-caused deaths that results from the rapid consumption or caching of most depredated carcasses. Predation is, therefore, likely to be a more significant cause of pink pigeon mortality than was indicated by this study.

Almost half of the recovered cadavers were from IAA, where carcasses are easier to locate due to the small size of this islet and because fewer scavenging animals are present than at mainland sites. However, despite being easier to find, biological remains at this site also deteriorate more rapidly in the higher coastal temperatures; hence the higher proportion of IAA pink pigeons for which cause of death could not be deter- mined. Trichomonosis was a probable cause of death in some of these cases; 2 carcasses were missing soft tissues around the head and throat region which, if they had died of trichomonosis, would further increase the proportion of birds lost to this disease.

The finding of several new parasite taxa in the pink pigeon is notable, as these pathogens may be recent additions to the parasite fauna of the pink pigeon, and future monitoring should investigate whether these increase in prevalence over time. The subcutaneous mites found in several IAA birds were not associated with histopathological changes but may be indicative of poor host condition. The trematode genus Paratanasia has been recorded in pigeons in South America and the Philippines and may have been introduced to Mauritius with exotic species. Trematode infection (possibly with the same trematode species) has been recorded on one other occasion in a pink pigeon from another subpopulation (PW), which died in 2001 (MWF unpubl. necropsy report). The intermediate host of this parasite is probably an introduced land snail (Subulina octo). However, nothing is known about the life-cycle/occurrence of this species in Mauritius, so it would be interesting to investigate the parasite's occurrence in other introduced columbid species to assess any potential threat it may pose to the pink pigeon. The heavy cestode infection is the first published record of tapeworms in the pink pigeon. It was not possible to identify this cestode to species level. Future disease studies on the pink pigeon should include faecal screening to determine how widespread these and other helminth species are across the 5 subpopulations.

In their review of disease as a cause of extinctions and endangerment, Smith et al. (2006) found little conclusive evidence supporting infectious disease as a contributory threat for the majority of species studied, and highlighted the need for specific knowledge of contributing factors. It is often difficult to attain such information in the case of disease, but studies such as ours, concerning pathogen screening or causes of mortality, are crucial for endangered species conservation. It is true that mortality studies based on opportune carcass findings in the wild are subject to inevitable biases and that these biases may result in, for example, the role of disease being overestimated and that of predation underestimated in mortality. However, they also provide invaluable data for assessing the role of disease as a cause of the population dynamics of endangered species.

Necropsy studies are easier to conduct in captive populations, due to the rapid recovery of carcasses, well-documented individual veterinary histories and superior facilities compared to those in field conditions. However, captive studies should supplement and not replace field studies of free-living populations since 
they may also misrepresent causes of mortality in freeliving birds.

In summary, despite the unavoidable biases and the relatively small sample sizes usually involved, mortality studies of free-living birds play an important role in wildlife disease research (Deem et al. 2001) and provide valuable information on significant mortality factors which may otherwise be overlooked. Ideally, postmortem studies of endangered species should be conducted in parallel with disease studies of live birds in the same population. Such studies require interdisciplinary expertise from field conservation biologists, ecological epidemiologists and veterinarians.

Acknowledgements. We thank the National Parks and Conservation Service of Mauritius for their support with the pink pigeon conservation programme, and staff of the Mauritian Wildlife Foundation, in particular, V. Tatayah and I. Lenoir, for logistic, administrative and financial support. E. Harris of the Parasitology Unit at the Natural History Museum, London, UK, assisted with the identification of the renal trematode and provided Fig. 2A. Additional financial support was provided by Chester Zoo, UK, and N.B. was funded by a BBSRC studentship (\#01/A1/S/07133).

\section{LITERATURE CITED}

Atkinson IAE (1996) Introductions of wildlife as a cause of species extinctions. Wildl Biol 2:135-141

Bunbury N (2006) Parasitic disease in the endangered Mauritian pink pigeon Columba mayeri. PhD dissertation, University of East Anglia, Norwich

Bunbury N, Barton E, Jones CG, Greenwood AG, Tyler KM, Bell DJ (2007) Avian blood parasites in an endangered columbid: Leucocytozoon marchouxi in the Mauritian pink pigeon Columba mayeri. Parasitology 134:797-804

Bunbury N, Jones CG, Greenwood AG, Bell DJ (2008) Epidemiology and conservation implications of Trichomonas gallinae infections in the endangered Mauritian pink pigeon. Biol Conserv 141:153-161

Conti JA (1993) Disease, parasites and contaminants. In: Baskett TS, Sayre MW, Tomlinson RE, Mirarchi RE (eds) Ecology and management of the mourning dove. A Wildlife Management Institute Book. Stackpole Books, Harrisburg, PA, p 205-224

Cooper JE (2004) Information from dead and dying birds. In: Sutherland WJ, Newton I, Green RE (eds) Bird ecology and conservation: a handbook of techniques. Oxford University Press, Oxford, p 179-209

Deem SL, Karesh WB, Weisman W (2001) Putting theory into practice: wildlife health in conservation. Conserv Biol 15:1224-1233

Forrester DJ, Foster GW (2008) Trichomonosis. In: Atkinson CT, Thomas NJ, Hunter DB (eds) Parasitic diseases of wild birds. Blackwell Publishing, Ames, IA

Friend M, McLean RG, Dein FJ (2001) Disease emergence in birds: challenges for the twenty-first century. Auk 118: 290-303

Editorial responsibility: Andrew Cunningham,

London, UK
Gaspar da Silva D, Barton E, Bunbury N, Lunness P, Bell DJ, Tyler KM (2007) Molecular identity and heterogeneity of trichomonad parasites in a closed avian population. Infect Genet Evol 7:433-440

Greiner EC, Baxter WL (1974) A localised epizootic of trichomoniasis in mourning doves. J Wildl Dis 10:104-106

> Harmon WM, Clark WA, Hawbecker AC, Stafford M (1987) Trichomonas gallinae in columbiform birds from the Galapagos Islands. J Wildl Dis 23:492-494

Höfle U, Gortazar C, Ortíz JA, Knipsel B, Kaleta EF (2004) Outbreak of trichomoniasis in a woodpigeon (Columba palumbus) wintering roost. Eur J Wildl Res 50:73-77

Jones CG (1987) The larger land-birds of Mauritius. In: Diamond AW (ed) Studies of Mascarene Island birds. Cambridge University Press, Cambridge, p 208-300

Jones CG (2004) Conservation management of endangered birds. In: Sutherland WJ, Newton I, Green RE (eds) Bird ecology and conservation: a handbook of techniques. Oxford University Press, Oxford, p 269-301

Jones CG, Hartley J (1995) A conservation project on Mauritius and Rodrigues: an overview and bibliography. Dodo J Wildl Preserv Trusts 31:40-65

> Krone O, Altenkamp R, Kenntner N (2005) Prevalence of Trichomonas gallinae in northern goshawks from the Berlin area of northeastern Germany. J Wildl Dis 41:304-309

Osofsky SA, Karesh WB, Deem SL (2000) Conservation medicine: a veterinary perspective. Conserv Biol 14:336-337

Peirce MA, Greenwood AG, Swinnerton KJ (1997) Pathogenicity of Leucocytozoon marchouxi in the pink pigeon (Columba mayeri) in Mauritius. Vet Rec 140:155-156

Real J, Mañosa S, Muñoz E (2000) Trichomoniasis in a Bonelli's eagle population in Spain. J Wildl Dis 36:64-70

Rose K (2005) Wildlife health investigation manual 2005. The Australian registry of wildlife health. Zoological Parks Board of New South Wales, Sydney

Roy SS (2001) The ecology and management of the lesser Indian mongoose Herpestes auropunctatus on Mauritius. $\mathrm{PhD}$ dissertation, University of Bristol

Samour JH (2000) Supraorbital trichomoniasis infection in two saker falcons (Falco cherrug). Vet Rec 146:139-140

Santos V (1934) Monostomose renal das aves domésticas. Rev Dep Nac Prod Animal 1:203-211

Schulz JH, Bermudez AJ, Millspaugh JJ (2005) Monitoring presence and annual variation of trichomoniasis in mourning doves. Avian Dis 49:387-389

Smith KF, Sax DF, Lafferty KD (2006) Evidence for the role of infectious disease in species extinction and endangerment. Conserv Biol 20:1349-1357

Stabler RM (1954) Trichomonas gallinae: a review. Exp Parasitol 3:368-402

Swinnerton KJ, Greenwood AG, Chapman RE, Jones CG (2005a) The incidence of the parasitic disease trichomoniasis and its treatment in reintroduced and wild pink pigeons. Ibis 147:772-782

> Swinnerton KJ, Peirce MA, Greenwood AG, Chapman RE, Jones CG (2005b) Prevalence of Leucocytozoon marchouxi in the endangered pink pigeon Columba mayeri. Ibis 147:725-737

Waine JC (1996) Post-mortem examination technique. In: Beynon PH, Forbes NA, Harcourt-Brown NH (eds) Manual of raptors, pigeons and waterfowl. British Small Animal Veterinary Association, Cheltenham, p 98-109

Weimerskirch H (2004) Diseases threaten Southern Ocean albatrosses. Polar Biol 27:374-379

Submitted: October 15, 2007; Accepted: February 26, 2008

Proofs received from author(s): April 17, 2008 